\title{
Religião, cultura, nação: articulações possíveis a partir de três datas comemorativas
}

Religion, culture, nation: possible articulations from three commemorative days

\author{
Izabella Bosisio* \\ * Universidade Federal do Rio Grande do Sul - Porto Alegre, RS, Brasil \\ Doutoranda em Antropologia Social (bolsista Capes) \\ izabellabosisio@yahoo.com.br
}




\title{
Resumo
}

O artigo propõe pensar os usos e sentidos de cultura mobilizados em disputas em torno da ocupação do tempo público, bem como as possíveis articulações e deslocamentos entre as categorias de religião, cultura e nação, a partir de uma comparação entre três casos de datas comemorativas brasileiras: o feriado de Nossa Senhora Aparecida, o Dia do Evangélico e o Dia da Consciência Negra. Tomando como base um mapeamento da legislação e do processo legislativo sobre a institucionalização de feriados no calendário oficial brasileiro, podemos observar como datas religiosas são fortemente imbricadas com uma ideia de tradição e de costumes populares. O que se coloca como um elemento de construção da identidade nacional brasileira é o catolicismo, como observamos nas discussões sobre o feriado de Aparecida. O Dia do Evangélico e o da Consciência Negra trariam outros elementos para o calendário nacional, acionando-se também categorias como etnicidade, diversidade, maioria e minoria.

Palavras-chave: calendário; religião; cultura; nação.

\begin{abstract}
The article proposes to think the uses and senses of culture mobilized in disputes around the occupation of public time, as well as the possible articulations and displacements between the categories of religion, culture and nation, from a comparison between three cases of Brazilian commemorative days: the holiday of Our Lady of Aparecida, the Day of the Evangelical and the Day of Black Consciousness. Based on a mapping of legislation and the legislative process on the institutionalization of holidays in the Brazilian official calendar, we can observe how religious days are strongly interwoven with an idea of tradition and popular customs. What stands out as an element of construction of the Brazilian national identity is Catholicism, as we observed in the discussions about the holiday of Aparecida. The Day of the Evangelical and the Day of the Black Consciousness would bring other elements to the national calendar, triggering also categories such as ethnicity, diversity, majority and minority.
\end{abstract}

Keywords: calendar; religion; culture; nation. 


\section{Introdução ${ }^{1}$}

Quais os deslocamentos e articulações possíveis entre as noções de cultura e de religião? Certamente são diversos, assim como os usos e sentidos de cada uma dessas categorias. A fim de dar conta de algumas dessas possibilidades dentro de um quadro tão variado, minha proposta é pensar concretamente os sentidos de cultura mobilizados em disputas em torno da ocupação do tempo público ao mesmo tempo que as relações que podem se desenvolver entre religião e cultura nesse contexto. Para tanto, me deterei em uma comparação entre três casos de institucionalização de datas comemorativas presentes no calendário brasileiro: o feriado de Nossa Senhora Aparecida, o Dia do Evangélico e o Dia da Consciência Negra. Como veremos, esses casos acionam também outras categorias, como nação e identidade nacional, tradição, etnicidade, diversidade e as noções de maioria e minoria.

Datas comemorativas e particularmente feriados provocam questões em diferentes planos, com argumentos sobre economia, trabalho, direito, civismo, turismo, tradição, cultura, religião. Um ponto que já podemos destacar é que há uma articulação entre religião e tradição na própria legislação sobre a instituição de feriados civis e religiosos no Brasil, que possuem classificações separadas, embora haja um entrelaçamento entre as duas categorias em diversos momentos. Resumidamente, de acordo com a lei federal n ${ }^{\circ}$ 9.093, de 1995 (Brasil, 1995), a União e os estados da federação podem estabelecer feriados civis²

1 Este artigo é uma versão aprimorada de um trabalho de fim de curso elaborado para a disciplina Sociedade e Cultura no Brasil, oferecida em 2016 pelo Programa de Pós-Graduação em Antropologia Social da Universidade Federal do Rio Grande do Sul (PPGAS/UFRGS) e ministrada por Emerson Giumbelli, a quem agradeço pelos comentários e sugestões sempre preciosos. Posteriormente, ainda em 2016, o trabalho foi apresentado no VI Simposio Internacional sobre Religiosidad, Cultura y Poder (VI SIRCP del GERE), ocorrido em Niterói, Rio de Janeiro. Agradeço também pelas considerações dos/as pareceristas de Horizontes Antropológicos, que me possibilitaram aprimorar alguns pontos. A maior parte do trabalho aqui publicado foi realizada com o apoio do CNPq, por meio de bolsa de mestrado, no Programa de Pós-Graduação em Antropologia Social do Museu Nacional da Universidade Federal do Rio de Janeiro (PPGAS/ MN/UFRJ), e, mais recentemente, seu desenvolvimento conta com o apoio da Capes, através de bolsa de doutorado, no PPGAS/UFRGS.

2 Os municípios podem instituir feriados civis apenas nos dias do início e do término do ano do centenário de sua fundação, o que é um fator limitador, embora consigam estabelecer feriados desse tipo através de manobras e reinterpretações da lei federal - ver mais sobre isso em Bosisio (2014). 
- sendo, no âmbito destes últimos, apenas relativos à data magna de cada localidade -, ao passo que os de caráter religioso ficam a cargo dos municípios, conforme uma tradição local e com um limite de quatro datas, nestas incluída a Sexta-Feira da Paixão.

Acompanhando a tramitação de vários projetos de lei sobre o calendário, em um período que inclui desde meados da década de 1940 até o início dos anos $2010,{ }^{3}$ podemos perceber que, em muitos casos, a religião não aparece nominalmente nos debates, sendo conjugada com outras marcas, como tradição, história, cultura; mesmo que se admita que a data é religiosa, o fundamento para instituí-la como feriado não é religioso, ou não é apenas religioso. Nos debates legislativos, os feriados religiosos são fortemente imbricados com uma ideia de tradição e de costumes populares. E, nesse sentido, a formação da nacionalidade, do espaço e do tempo público, e do próprio Estado, não é concebida como possível sem que haja uma associação com a religião, mesmo que em alguns momentos ela apareça "disfarçada" ou até ressignificada em outra categoria para justificar sua presença. No caso brasileiro, o que se coloca como um elemento dessa construção da identidade nacional é o catolicismo, sendo mais facilmente incorporado ao ser entendido como parte das tradições e da cultura. E isso pode ser observado nas discussões sobre o feriado de Nossa Senhora Aparecida.

Por outro lado, debates como o que cerca o Dia do Evangélico, como um dia específico de homenagens à comunidade evangélica, são um exemplo da emergência de argumentos em prol da diversidade cultural e religiosa do país, embora ainda se mantendo no âmbito cristão. Nesse mesmo sentido, das tentativas de instituição de novos marcos para o calendário nacional e do reconhecimento e representação de outros atores e dimensões, temos os debates em torno do Dia da Consciência Negra. Na Constituição Federal de 1988, as datas comemorativas são atreladas à etnicidade, sugerindo uma concepção

3 O levantamento de projetos de lei sobre feriados, assim como da legislação já estabelecida, fez parte da minha dissertação de mestrado (Bosisio, 2014) e foi realizado no site da Câmara dos Deputados (http://www2.camara.gov.br/). Ressalto que as datas estão de acordo com o material disponível na base oficial da Câmara, o que não significa a inexistência de proposições relacionadas à temática dos feriados e do calendário em outros períodos de tempo. 
de nação formada por diferentes grupos étnicos. ${ }^{4} \mathrm{O}$ Dia da Consciência Negra nos traria, então, mais essa dimensão. Alguns argumentos favoráveis à sua institucionalização como feriado ou data comemorativa indicam que a data não é de interesse exclusivo da comunidade afro-brasileira, sendo de grande importância para toda a nação, como símbolo de liberdade e de luta por direitos fundamentais. Além disso, como veremos, lembra-se da enorme influência do povo negro para a formação do Brasil e destaca-se o respeito pelas diferenças e diversidade étnico-cultural. Há muitas discussões sobre o caráter dessa data e que envolvem também sua possível dimensão religiosa. O debate em torno de sua (in)constitucionalidade em muitos locais tem a ver, dentre outros aspectos, com a lei federal sobre feriados e com o limite de quatro datas (religiosas) para os municípios. Isso foi motivo de controvérsia, por exemplo, em Porto Alegre, capital do Rio Grande do Sul.

Com base nesse contexto de discussões, o ponto de partida para minha investigação será o debate sobre o conceito de cultura e seus múltiplos sentidos, considerando que feriados e datas comemorativas instituídos são pensados como parte da construção da identidade cultural de uma nação. Diria, inclusive, que essas datas, em especial os feriados - mais significativos por serem dias de não trabalho, em que se paralisa o tempo comum -, poderiam ser adicionadas àqueles elementos indicados por Benedict Anderson (2008) como instrumentos utilizados pelo Estado para produzir uma imagem da nação. O autor mostra como os censos, os mapas e os museus são instituições que moldam imaginações, conforme a maneira como o Estado imagina seu domínio. Cabe lembrar aqui também do destaque dado aos museus por Roy Wagner (2010) como exemplos de instituições culturais, que apresentariam uma parte do que se considera a cultura mais geral de uma sociedade, cultura entendida como modo de vida. Os museus articulariam alguns sentidos de cultura, preservando e sustentando ("metaforizando") os resultados de um processo

4 Na Constituição, em seção sobre cultura, apenas um artigo, em um único parágrafo, aborda as datas comemorativas, relacionadas aos segmentos étnicos, mas de forma geral e abstrata: "Art. 215. O Estado garantirá a todos o pleno exercício dos direitos culturais e acesso às fontes da cultura nacional, e apoiará e incentivará a valorização e a difusão das manifestações culturais. [...] $\S 2^{\circ}$ A lei disporá sobre a fixação de datas comemorativas de alta significação para os diferentes segmentos étnicos nacionais" (Brasil, 2012). 
de refinamento do homem. Essa ideia de refinamento é estendida aqui para o coletivo, referindo-se, assim, ao uso antropológico da "cultura". Nesse contexto, podemos pensar igualmente em Wagner na dimensão da cultura em relação com o Estado, o que envolve uma espécie de pedagogia; a ideia de cultura como modo de vida alimenta, afinal, a ideia de nação e sua construção. Assim, temos essa dimensão política da cultura, utilizada com o intuito de conferir uma "unidade social" (Eagleton, 2003, p. 42).

Com isso, sugiro que o calendário seja pensado também como uma dessas instâncias de construção do poder do Estado mencionadas por Anderson, fazendo parte dessa imaginação da nação e transformando datas em eventos nacionais - algo que já foi apontado por Jacques Le Goff $(1984$, p. 260) ao tratar das relações entre tempo e poder, afirmando como "o calendário é um dos grandes emblemas e instrumentos de poder", poder este religioso ou laico. O tempo também faz parte de um jogo político. Nesse sentido, o calendário pode ser igualmente pensado como um outro espaço no qual atores distintos disputam seu direito de representação. Lembro, nesse aspecto, da ideia defendida por Peter Häberle (2008) de um direito ao feriado como um dos elementos de identidade cultural do Estado constitucional. No entanto, essa identidade cultural pode dizer respeito não apenas a algo que passaria por uma construção nacional, mas a uma pluralidade de culturas ou manifestações culturais (incluindo as religiosas) presentes num mesmo território, cabendo destacar como "a religião passou a desempenhar um papel nas estratégias de atribuição e adoção de identidades coletivas" (Giumbelli, 2002, p. 25). Ou seja, a diversidade pode propiciar afirmações de identidade(s) cultural(ais). Disso se depreendem debates que envolvem "reivindicações da cultura", demandas por reconhecimento (seja da dimensão religiosa, de algo como manifestação cultural, seja no campo da etnicidade), o que abarca uma espécie de politização da noção de cultura e uma aproximação entre direitos (ou noções de direito) e cultura, elaborando-se a ideia de direitos culturais.

Aqui já podemos atentar para a multiplicidade de usos e sentidos do termo "cultura". Terry Eagleton (2003) e Raymond Williams (2007), por exemplo, destrincham o conceito a partir de uma visão histórica, identificando essa diversidade de sentidos em diferentes momentos e contextos e mapeando as transformações e ressignificações de seus usos, de algo referente à agricultura, a um cultivo e à colheita, passando pelo refinamento da "sala de ópera" destacada igualmente por Wagner (2010) e outro sentido de cultivo, até chegar 
ao seu sentido antropológico, com uma democratização dessa ideia de refinamento, conforme sugeri acima, com uma passagem de algo singular para algo plural - de "cultura" para "culturas", com um registro da pluralidade de modos de vida. Dessa forma, a ideia de que há versões da cultura evidencia como o conceito é objeto de disputas.

É nesse sentido que podemos falar também de uma politização da "cultura", cujos usos por indivíduos e grupos distintos, com interesses variados, produzem efeitos no mundo da política, com o conceito de cultura sendo mobilizado como uma espécie de ferramenta, conforme analisa Susan Wright (1999), em especial em processos que envolvem atores excluídos ou marginalizados. Isso nos remete à ideia de cultura com aspas de Manuela Carneiro da Cunha (2009), considerando que, em muitas dessas situações, o conceito é operado de forma objetivada e autoconsciente, chegando a apresentar um aspecto performatizado ao assumir um papel de argumento político. Ou seja, podemos observar a instrumentalização da cultura em ações tanto do Estado quanto da sociedade civil, tomando a cultura como uma "arma" de agenciamento de grupos, como destaca Clara Mafra (2011), ou como um recurso político, como também indica Joanildo Burity (2008).

Poderíamos pensar nos casos em análise neste trabalho nesses termos? Como os atores em destaque, em especial as denominações religiosas, operam com a ideia de cultura? Dessa forma, para o presente texto, procurarei observar quais são os sentidos de religião e cultura em cada um dos casos de datas comemorativas e considerando que se referem a públicos ${ }^{5}$ que envolvem diferentes maneiras de articular a cultura e distintos lugares na ideia de nação, ou seja, cada público apresenta uma posição (e constrói também essa posição, sem deixar de considerar aqui as suas distinções internas e de constituição) no que se imagina como nação brasileira. Esta investigação terá como objeto principalmente um material legislativo, verificando-se como esses debates ocorrem no próprio processo de institucionalização de uma nova data no calendário oficial brasileiro. Para fins deste texto, a ênfase será dada sobre as normas já aprovadas e que estabeleceram as datas referidas. Eventualmente, projetos de lei mais recentes serão analisados de forma breve.

5 Para uma análise sobre a constituição de públicos, ver, por exemplo, a abordagem de Michael Warner (2002). 


\section{Feriado de Nossa Senhora Aparecida: quando a religião também é cultura}

O papa Pio XI consagrou, em 1930, Nossa Senhora Aparecida, ou Nossa Senhora Conceição Aparecida, como padroeira principal do Brasil. Em 31 de maio de 1931, no Rio de Janeiro, diante do presidente Getúlio Vargas e de autoridades civis e militares, Dom Sebastião Leme a proclamou como Rainha e Padroeira do Brasil. A consagração de Aparecida como padroeira é muito significativa no que tange às relações entre a Igreja Católica e o Estado brasileiro, com a República ainda nascente, em que observamos uma disputa em torno da nacionalidade e da representação da nação brasileira, pensada como essencialmente católica.

A devoção a Nossa Senhora passou por várias datas, mas sua festa acabou fixada para 7 de setembro. Em 1953, confirmou-se sua celebração no dia 12 de outubro, escolhido, segundo Rubem César Fernandes (1988, p. 90), "graças a uma resolução da Conferência Nacional dos Bispos do Brasil, que, afastando-a da festa da Independência, aproximava-a, mais remotamente, à festa da 'descoberta' das Américas", ${ }^{6}$ marcando, nesse sentido, o lugar do catolicismo na formação do Brasil. Apenas em 1980, a lei nº 6.802 (Brasil, 1980) instituiu um feriado nacional para Aparecida.

Essa norma teve como projeto de origem o projeto de lei (PL) 220/1979, de autoria do deputado Jorge Arbage (Partido Democrático Social/Pará). Apresentado em março de 1979, o projeto teve uma tramitação de um ano e três meses, aprovado e transformado em lei em 30 de junho de 1980, exatamente o mesmo dia em que o papa João Paulo II chegou ao Brasil, em sua primeira visita ao país. Em seu artigo $1^{\circ}$, o projeto original declarava o feriado nacional "para culto público e oficial a Nossa Senhora Aparecida". $\mathrm{O}$ artigo $2^{\circ}$ deixava a cargo do Ministério da Educação e Cultura (MEC) a promoção de festividades para celebrar o dia em estabelecimentos de ensino, onde as homenagens deveriam ser em hora diversa da festa litúrgica oficial das igrejas, e contando com a presença de autoridades eclesiásticas, civis e militares, nacionais e estrangeiras. Assim,

6 Cabe destacar que o 12 de outubro já fez parte, anteriormente, do calendário brasileiro como feriado pela "descoberta da América". 
sob os cuidados do MEC, tal feriado religioso ganhava um caráter cultural que precisava ser transmitido através das escolas.

Na justificação do projeto, Jorge Arbage indicava que, como Aparecida era padroeira do Brasil, competia declarar o seu dia feriado nacional, "para que a Nação inteira - com as atividades laborais interrompidas em tal data - se alie à Igreja de Deus, para louvá-la reconhecida, justa e detidamente, agradecendo-lhe as graças que nos concede tão generosamente". O deputado lembrava que, em 1976, apresentara o PL 3.071, o qual também instituía o dia 12 de outubro como feriado. Apesar de ser aprovado na Câmara, este foi rejeitado no Senado, sob a alegação de que tínhamos excesso de feriados. A respeito disso, Arbage argumentava que o país tinha apenas nove feriados, sendo cinco de cunho religioso, o que, segundo ele, nos levava a constatar que "a Nação brasileira é eminentemente católica". O deputado pareceu bastante decepcionado pelo fato de os senadores não terem feito nenhuma referência ao caráter religioso do projeto, ou, como ele dizia, à "latitude e altitude da beatífica meta sobremirada no projeto". Para o parlamentar, não haveria problema em reservar um dia do ano para um culto mais intenso à Aparecida, já que muitos brasileiros suspendiam o trabalho no dia 12 para se dedicarem à santa. Dessa forma, o feriado seria uma oportunidade "para que o Brasil inteiro disponha de tempo para se prostrar aos pés de sua Padroeira - Nossa Senhora Aparecida, agradecendo-lhe, penhoradamente, tudo que há feito, e o quanto ainda poderá prodigalizar em benefícios ao Povo Brasileiro".

Durante a tramitação do projeto na Câmara e no Senado Federal, podemos verificar alguns argumentos favoráveis e outros contrários a ele. Dentre os favoráveis, o discurso era de que o culto à santa atenderia "a um verdadeiro sentimento nacional", estendendo-se por todo o país e todas as camadas sociais. A ideia de que "somos católicos" foi reforçada, sendo o projeto considerado como possuidor de um significado educacional, de espiritualidade, e cívico, já que "as raízes históricas brasileiras estão muito ligadas aos sentimentos católicos", com um discurso que reafirmava a ideia de essência católica da nação brasileira. Como se ressaltou nas apreciações sobre o projeto, o Brasil "nasceu com a Igreja Católica e hoje possui a maior comunidade católica do universo".

Nas argumentações contrárias ao feriado, observam-se discursos de que o Estado deveria respeitar todas as conviçcões, assim como respeita a dos católicos, com questionamentos referentes à promoção de festividades que 
propagariam uma determinada religião. Além disso, refutava-se o artigo $2^{\circ}$ do projeto original, que deixava essas festividades nas escolas a cargo do MEC. Conforme se argumentou, isso não estaria de acordo com o Estado laico e com o "caráter da sociedade brasileira, que todos desejamos pluralista e democrática", podendo trazer complicações práticas para alunos(as) não católicos(as) e escolas confessionais não católicas. Ao passar pelo Senado, este artigo foi suprimido da proposição. Aprovado, o feriado de Aparecida é o único que não consta na norma federal que declara todos os feriados nacionais, a lei $\mathrm{n}^{\circ} 662$, de 1949 (Brasil, 1949), atualizada pela última vez em 2002. A "padroeira do Brasil" permanece com uma norma exclusiva e destacada das demais normas sobre o calendário nacional.

Outras proposições relativas ao feriado de Nossa Senhora Aparecida foram apresentadas ao longo das décadas seguintes, em geral pretendendo revogá-lo, ou, ao menos, alterar sua comemoração. Os argumentos em prol da revogação do feriado envolviam a problemática do culto público e oficial à santa, classificado como uma afronta a princípios referentes ao Estado - ao qual é vedado o estabelecimento de cultos religiosos - e ao indivíduo - no que diz respeito ao direito à liberdade religiosa. Apenas um projeto propunha uma alteração na lei de 1980 - o PL 2.623/2007 -, mantendo o feriado, mas com duas diferenças: a expressão "padroeira do Brasil" era substituída por "padroeira dos brasileiros católicos apostólicos romanos"; e o "culto público e oficial" era substituído por "homenagem oficial". Basicamente, o intuito era democratizar o conteúdo da norma, entendida como inconstitucional, fazendo com que se promovesse a igualdade entre os cidadãos e procurando ainda respeitar "a tradição do povo brasileiro, em que a religião faz parte sistemática da cultura nacional".

Isso nos remete a uma ideia de "cultura católico-brasileira", discutida por Pierre Sanchis (1994), em que o catolicismo conseguiu encarnar a totalidade da nação, com referência a um passado do país e à sua constituição histórica, além de uma certa diluição do catolicismo na sociedade brasileira, ainda marcando a identidade nacional, a matriz cultural brasileira e o campo religioso. Esse movimento da religião para a cultura também está presente nas discussões de Lori Beaman (2012), que observa, no campo de estudos sobre símbolos religiosos no espaço público, como a hegemonia de uma maioria religiosa pode ser preservada em nome da cultura, abrindo espaço para a ideia de que os valores religiosos são valores universais. A noção de uma essência católica brasileira 
e de que há um verdadeiro sentimento nacional ligado ao catolicismo e ao culto a Nossa Senhora Aparecida podem ser exemplos nesse contexto.

Segundo Erin Wilson (2014) e conforme debatemos ao longo do texto, a identificação de algo como cultura tem a ver com a construção de uma identidade que é tida (ainda - como no caso do catolicismo no Brasil e do feriado de Nossa Senhora Aparecida, por exemplo) como importante para o presente. Mas, como a autora ressalta, quando falamos do cristianismo, e mais especificamente do catolicismo aqui, como nossa cultura, olhamos apenas para uma parte da identidade. "Quem é excluído, mesmo que sutilmente, quando celebramos o cristianismo como cultura, e não como religião?", ela questiona (Wilson, 2014, tradução minha). Cabe destacar que, afinal, a passagem da religião para a cultura também é um artifício de disputas, com um uso político que envolve dimensões e definições de pertencimentos, significados, ideias e projetos políticos. Isso nos conduz à próxima data comemorativa.

\section{Dia do Evangélico: quando a religião precisa ser cultura}

O Dia Nacional do Evangélico, comemorado em 30 de novembro, foi instituído em 2010, através da lei $\mathrm{n}^{\circ} 12.328$ (Brasil, 2010). Apresentada dois anos antes, sua proposição (PL 3.541/2008), de autoria do deputado Cleber Verde (Partido Republicano Brasileiro/Maranhão), reservava o dia também para sessão solene no Congresso Nacional, em que seriam realizadas homenagens aos evangélicos, o que, no entanto, foi excluído do texto final da lei.

Em justificação à proposta, Verde utiliza dados de pesquisas do Instituto de Estudos da Religião (Iser) e do censo demográfico do Instituto Brasileiro de Geografia e Estatística (IBGE), indicando que "o país mais católico do mundo está ficando cada vez mais evangélico". O parlamentar também apresenta alguns contrastes entre católicos e evangélicos, a fim de demonstrar o valor de suas crenças e práticas. Afirma que "os evangélicos levam sua prática de fé a sério", mais do que os católicos, em geral por terem passado por processos de conversão. Ademais, participariam com mais regularidade de cerimônias e obras sociais, além de "proliferarem em todas as camadas sociais", produzindo mudanças como, por exemplo, sua maior presença na cena pública, com "grandes manifestações de fé". O deputado destaca ainda que o Dia do Evangélico 
já é comemorado em outras localidades, como o estado do Amapá, sendo, inclusive, feriado no Distrito Federal, onde era celebrado como data comemorativa, segundo ele, desde 1956. Finaliza, assim, reconhecendo a laicidade do Estado brasileiro, mas observando que pretendia "homenagear esse segmento que vem crescendo substancialmente em todo o país".

Na tramitação do projeto, destaca-se o argumento do impacto da participação dos evangélicos na sociedade brasileira, que, além da expansão numérica, incluiria a ocupação de espaços na "política, na mídia, no esporte e na cultura" e a disseminação pelas igrejas evangélicas de "elevados valores de família, vida, ética e fé".

Observo que, em anos anteriores, outras três proposições sobre o Dia do Evangélico foram apresentadas na Câmara dos Deputados, incluindo uma tentativa de instituí-lo como feriado nacional. Em geral, as argumentações giravam em torno do crescimento da parcela evangélica, marcando também a importância da religiosidade como uma das manifestações culturais da população, além da ideia de que as datas comemorativas seriam instrumentos de afirmação da identidade cultural de um povo, considerando que as propostas pelo Dia do Evangélico estariam de acordo com esse preceito. Embora esses projetos tenham sido rejeitados e arquivados em 2010, em muito devido à aprovação da lei discutida acima, há de se destacar a quantidade de proposições seguidas sobre o Dia do Evangélico, demonstrando uma certa urgência na instituição da comemoração, consoante o aumento quantitativo e também de visibilidade do segmento evangélico nos últimos anos. O feriado nacional não foi admitido, mas sua data comemorativa já marca presença no calendário.

O feriado do Dia do Evangélico, porém, ocorre em alguns estados e municípios brasileiros, como no Acre e em sua capital Rio Branco (em 23 de janeiro), em Rondônia (em 18 de junho) e, conforme indicado, no Distrito Federal (em 30 de novembro), sendo ponto facultativo no estado do Amapá (também em 30 de novembro). Embora a data represente uma forma de reconhecimento da comunidade evangélica e de seu crescimento nas estatísticas e na cultura brasileira, o feriado não é unânime no meio evangélico, já que, para alguns, não simbolizaria nenhuma data significativa para o grupo em geral; afinal, a comunidade evangélica é extremamente diversificada. No entanto, o feriado tem sua relevância na medida em que evangélicos, em especial pertencentes a vertentes pentecostais, se fazem cada vez mais presentes e visíveis na esfera pública. 
Em certo sentido, esse reconhecimento pode ser entendido como uma contestação à ideia de uma essência católica da nação brasileira, cujas representações estariam se modificando. Essas transformações no campo religioso brasileiro, de acordo com Carlos Steil (2001), exporiam "uma crescente pluralidade religiosa dentro de uma nação que se constituiu incorporando a unidade religiosa como um elemento central de sua identidade" (Steil, 2001, p. 9). Particularmente, o pentecostalismo, como Sanchis (1994) observa, viria para transformar o que ele chama de "cultura católico-brasileira", alterando os princípios mesmos que ordenam sua estrutura. Apesar disso e de uma diminuição da hegemonia católica, o autor atenta para o fato de que a imagem da relação entre o catolicismo e o Brasil ainda permanece, de modo latente ou explícito. Da mesma maneira, Steil (2001) também verifica as permanências do catolicismo na cultura brasileira, em especial os seus elementos inconscientes.

Embora tanto o Dia do Evangélico quanto o feriado de Nossa Senhora Aparecida permaneçam em um âmbito cristão, é interessante apontar para a complexa relação das noções de maioria e minoria que esses dois exemplos envolvem no que diz respeito aos argumentos da cultura e da religião. O estatuto do cristianismo oscila, ora se vendo como maioria, ora como minoria - minoria esta que seria ilegítima no espaço público, como muitas vezes se considera a respeito de evangélicos.

Dessa forma, como podemos pensar a apresentação da religião evangélica como parte do que seria a cultura brasileira, afirmando-se como uma "cultura", uma "manifestação cultural" cada vez mais presente? Para Mafra (2011), os evangélicos arriscam-se pouco na negociação que submete, mesmo que momentaneamente, o "religioso" ao "cultural", ao contrário dos católicos e dos afro-brasileiros, que conseguiriam se colocar como parte da cultura nacional mais facilmente, acionando até uma ideia de complementaridade na formação da nacionalidade, como explora Emerson Giumbelli (2014a). De acordo com a autora, é possível que os evangélicos estejam mais comprometidos com o futuro do que com o presente. Em outras palavras, eles pensariam em cultura olhando para frente, para algo a construir e constituir no futuro, assumindo a forma de uma "cultura pública" (Giumbelli, 2014a). Talvez a instituição do Dia do Evangélico faça parte desse projeto para o futuro, em que precisam se pensar como parte da cultura brasileira para inclusive serem "vistos" como religião, em contraste com o que ainda se entende por religião no Brasil, bastante associada 
ao catolicismo. Nesse sentido, o Dia do Evangélico toca mais ao catolicismo, tendo em vista que possui uma referência mais claramente religiosa, diferentemente do Dia da Consciência Negra.

\section{Dia da Consciência Negra: quando a religião faz parte da cultura}

A Consciência Negra é celebrada em 20 de novembro, data da morte do líder negro Zumbi dos Palmares. Assim, sua comemoração, instituída apenas em $2011^{7}$ através da lei $n^{\circ} 12.519$ (Brasil, 2011), faz referência ao Dia Nacional de Zumbi e da Consciência Negra. A data é feriado estadual em cinco estados brasileiros - Amazonas, Amapá, Mato Grosso, Alagoas e Rio de Janeiro -, sendo também feriado em centenas de municípios do país. Nas capitais, é feriado em Manaus, Cuiabá, Maceió, Rio de Janeiro e São Paulo. Tendo em vista a enorme adesão à data, diversos projetos de lei já tentaram instituí-la como feriado em nível nacional, dois estando ainda em andamento. Ressalto que Zumbi dos Palmares teve seu nome inscrito no "Livro dos Heróis da Pátria" em 1996, por meio da lei $n^{\circ} 9.315$ (Brasil, 1996), em comemoração ao tricentenário de sua morte, e o Dia da Consciência Negra foi incluído no calendário escolar com a lei $\mathrm{n}^{\circ} 10.639 / 2003$, que estabelece a obrigatoriedade do ensino do tema "História e Cultura Afro-Brasileira" (Brasil, 2003).

A proposição que deu origem à norma federal referente à data comemorativa foi apresentada primeiramente no Senado, ainda em 2003 (PLS 520), pela senadora Serys Slhessarenko (Partido dos Trabalhadores/Mato Grosso). A justificativa da parlamentar destaca as "raízes profundas" do preconceito entre os brasileiros, procurando desconstruir a ideia de que vige entre nós

7 Desde a década de 1980, as propostas de datas comemorativas e/ou feriados que pretendiam exaltar a comunidade afro-brasileira e aumentar a conscientização sobre sua importância na formação da nação e sobre a luta contra o racismo passaram a se voltar para o dia 20 de novembro. A comemoração nessa data teria sido idealizada em Porto Alegre, com a formação do Grupo Palmares, composto por intelectuais negros, no início da década de 1970, pretendendo-se registrar o 20 de novembro como referência para a comunidade negra, devido à sua simbologia relacionada à resistência e à luta do povo negro por liberdade e igualdade, e não o dia 13 de maio, que, embora seja um marco histórico (dia da abolição da escravidão no Brasil, em 1888), não representou uma ruptura real e prática com a desigualdade social e racial. 
uma democracia racial. Ela observa, assim, que o preconceito se apresenta em seu "modo de ser típico", não se reconhecendo a sua existência. Nesse sentido, a instituição de um Dia Nacional de Zumbi e da Consciência Negra não seria apenas uma homenagem aos afro-brasileiros, mas "um instrumento político para causar certos efeitos na cultura brasileira: estimular a identificação e o reconhecimento do preconceito (por todos: negros, brancos e pardos)". A comemoração, portanto, de acordo com Slhessarenko, teria um efeito simbólico e uma dimensão mobilizadora, além de se referir ao fenômeno da eclosão de uma "consciência negra", que viria ocorrendo na sociedade brasileira nas últimas décadas.

Em avaliação no Senado e na Câmara, observamos argumentos a favor da criação da data comemorativa, que demonstraria a "importância do negro e de suas lutas libertárias para a formação da nacionalidade", o que questionaria o imaginário dominante da sociedade brasileira. Destaca-se também que a data celebraria a herança histórica, a tradição e a resistência de negros e negras brasileiras, além de se destinar "à reflexão dos ideais de liberdade, fraternidade e igualdade".

Desde a década de 1980, porém, podemos identificar tentativas de se fixar o dia da Consciência Negra como feriado nacional. Os argumentos salientam igualmente o simbolismo da luta pela liberdade e por direitos fundamentais, ressaltando-se a importância do negro na formação da sociedade e da cultura brasileira. Atualmente, dois projetos com esse objetivo seguem em andamento na Câmara dos Deputados, ambos da atual década de 2010, posteriores à lei que instituiu a data comemorativa e com teores semelhantes, com destaque para a dívida que a sociedade brasileira ainda tem com a comunidade negra.

A dimensão religiosa presente no contexto envolvido pelas comemorações da Consciência Negra foi abordada pela primeira vez apenas na tramitação da proposição mais recente (PL 296/2015, de autoria do deputado Valmir Assunção, do Partido dos Trabalhadores/Bahia). No que concerne à resistência e à liberdade, argumenta-se como, historicamente, a prática de religiões de matriz africana era repudiada e como elas permanecem desvalorizadas; por isso, a criação de um feriado reconheceria a pluralidade existente, apoiando-se no direito à liberdade religiosa.

Nesse sentido, é oportuno discorrer sobre um caso mais recente de instituição desse feriado em âmbito municipal e que expõe mais claramente 
suas relações com a dimensão religiosa, ao contrário das outras centenas de ocorrências desse feriado em municípios pelo Brasil: em 2015, na cidade de Porto Alegre, capital do estado do Rio Grande do Sul, foi fixado o Dia da Consciência Negra e da Difusão da Religiosidade pela lei no 11.971 (Porto Alegre, 2015). A proposição original do vereador Delegado Cleiton (Partido Democrático Trabalhista/Rio Grande do Sul), apresentada em 2013, indicava a fixação do feriado sob o título apenas de Dia da Consciência Negra. Na exposição de motivos, o vereador argumenta que o feriado seria um marco histórico para a cidade, permitindo resgatar o legado do povo negro, "que sofreu por séculos com a escravidão e a discriminação racial em nosso país". Delegado Cleiton também afirma que o dia seria mais uma data para "propormos ações afirmativas de reparação social", enfatizando a "relevância da participação do negro por meio da cidadania, de sua cultura, de suas raízes e de sua história", além de, com a data, tentar "fortalecer a igualdade".

Ao projeto, foi rapidamente proposta uma emenda acrescentando o trecho "Difusão da Religiosidade", a fim de tentar evitar possível veto. Isso porque propostas semelhantes já haviam sido apresentadas antes (o feriado chegou a ser aprovado em 2003, mas sua norma foi revogada), sofrendo negativas justificadas pela lei federal no 9.093 (Brasil, 1995), citada anteriormente. Apesar dessa movimentação do vereador, o projeto foi vetado pelo então prefeito José Fortunati com a justificativa de que Porto Alegre já possuía quatro feriados municipais, referentes a Nossa Senhora dos Navegantes, Corpus Christi, Finados e Sexta-Feira da Paixão. Com isso, o mesmo vereador propôs uma alteração no calendário municipal, com a retirada do feriado de Finados, que é também feriado nacional, não trazendo consequências práticas. $\mathrm{O}$ feriado da Consciência Negra e da Difusão da Religiosidade foi, assim, aprovado, em votação que contou com a presença de representantes do movimento negro e das religiões de matriz africana no público, mas com a determinação, pela Câmara, de que a data fosse móvel, ocorrendo sempre no terceiro domingo do mês de novembro. Com a reação do movimento negro contrária a essa medida, logo os vereadores aprovaram a data fixa para 20 novembro. ${ }^{8}$

8 Mais informações sobre essa controvérsia do dia 20 de novembro em Porto Alegre podem ser vistas em: Após... (2015); Câmara... (2015); Melo (2015); Pagno (2015). 
O dia seria celebrado como feriado pela primeira vez em 2016, mas, assim como ocorreu em 2003 (pela Federação de Indústrias do Rio Grande do Sul), uma ação direta de inconstitucionalidade foi apresentada pelo Sindicato dos Lojistas do Comércio da cidade contra o feriado (ADIn 606/2016; processo $\mathrm{n}^{\circ} 70068409531$ - Rio Grande do Sul, 2016). O julgamento ocorreu no início do mês de novembro, e o Tribunal de Justiça do Rio Grande do Sul acatou a ação, considerando o feriado inconstitucional. Dentre os pontos discutidos no parecer da procuradoria-geral da Justiça, destaco o que aborda o termo "difusão da religiosidade". Segundo o parecer, a "simples menção genérica ao termo" não revestiria o feriado de características religiosas, "seja pela ausência de demonstração de que a data estabelecida configura dia de guarda de alguma religião, seja pelo manifesto objetivo de burlar decisão do Órgão Especial desse Tribunal de Justiça, que declarou inconstitucional lei anterior [norma de 2003 que criava o Dia da Consciência Negra em Porto Alegre]". Argumenta-se que a ideia de religiosidade aqui valorizaria o aspecto sociológico, com referência a um fenômeno humano geral, e não uma orientação religiosa particular. Isso tem a ver também com o fato de que, segundo a lei $n^{\circ} 9.093$ (Brasil, 1995), os feriados religiosos devem ser dias de guarda, de acordo com as tradições locais, e, nesse sentido, o dia 20 de novembro não seria um dia de guarda para denominação religiosa alguma, o qual se refere a um dia de preceito e de grande importância para determinada religião. Com isso, a inclusão do termo difusão da religiosidade, de acordo com o parecer, apenas teria objetivado conferir "um verniz de constitucionalidade ao feriado, criando a falsa impressão de que se trataria de data também com cunho religioso".

Ao entrevistar o vereador Delegado Cleiton ${ }^{9}$ logo após as comemorações da Semana da Consciência Negra em Porto Alegre, pude compreender melhor o que ele quis indicar com a expressão "difusão da religiosidade" atrelada à comemoração da Consciência Negra. O parlamentar afirmou que não foi uma estratégia para aprovar o feriado, como muitos pensaram e como "os lojistas colocaram". Segundo ele, a ideia era "trazer todas as religiosidades unidas [...] para dentro desse feriado", o que remeteria aos próprios quilombos, que reuniriam "todos os sofridos" e "suas culturas". Assim, a "difusão da religiosidade"

9 Entrevista realizada no gabinete do vereador Delegado Cleiton, na Câmara Municipal, em 21 de novembro de 2016, com uso de gravador. 
seria para todas as religiões, evitando que fosse mais um feriado apenas católico, como são todos os feriados religiosos de Porto Alegre e também os nacionais. A ideia, segundo o vereador, seria mesmo dar um tratamento igualitário a todas as religiões, sem destacar apenas as de matriz africana, o que o atrelamento com a Consciência Negra poderia indicar (o que foi também o que a maioria das pessoas imaginou). Mas, ao longo do processo em torno do feriado, na Câmara e no Tribunal, o que observamos é a participação ativa de pessoas ligadas às religiões de matriz africana, além do movimento negro, como já dito.

Com a revogação do feriado, Delegado Cleiton revelou que já estaria entrando com recurso através da representação de uma entidade religiosa, a Federação Afro Umbandista e Espiritualista do Rio Grande do Sul (Fauers), que acompanhou ativamente a ação na Justiça, para que o julgamento seja revertido e o feriado retomado. O recurso, encaminhado pela Câmara de Vereadores de Porto Alegre, foi julgado em maio de 2017, mantendo-se a revogação do feriado e reforçando-se argumentos do julgamento anterior. O vereador não foi reeleito nas eleições ocorridas em 2016, assim como alguns membros da então Frente Parlamentar em Defesa dos Povos Tradicionais de Matriz Africana, que incentivou a aprovação do feriado na Câmara. Com a mudança de legislatura, aliás, essa frente parlamentar se desfez, sendo instalada de novo em julho de 2017. Cabe agora acompanhar os próximos passos desse caso, procurando refletir sobre essas articulações com uma dimensão religiosa e sobre a dificuldade que se tem em aprovar esse feriado na cidade de Porto Alegre. Há uma expectativa também de que o feriado da Consciência Negra seja aprovado a nível federal, o que, porém, retiraria da cena a problemática em torno de seu aspecto religioso.

Além da dimensão de luta por direitos fundamentais que a comemoração do Dia da Consciência Negra envolve, observamos nos debates como o universo afro insere essa busca por reconhecimento no campo da etnicidade, fazendo parte de uma "cultura étnica" e apresentando-se como uma das parcelas que compõem o todo da nação (Giumbelli, 2014a). Nisso se incluem as religiões de matriz africana, que, para assegurar o estatuto de religião, precisaram se associar a uma herança africana, sendo reconhecidas por um viés "culturalista", como sugere Giumbelli (2008).

O sentido de cultura aqui é, portanto, marcado pela ideia de etnicidade e pela noção antropológica, pensando a cultura principalmente como tradição. 
A religião, assim, emerge como parte dessa tradição, desse legado. É nesse sentido também que se dá a passagem entre o religioso e o cultural no universo afro-brasileiro. E a ideia de uma "consciência negra", de uma herança africana na identidade brasileira, aciona muito o lugar da religião, como podemos observar nas comemorações em torno do dia 20 de novembro em todo o país.

\section{Considerações finais}

Finalizo as reflexões deste texto retomando alguns pontos sugeridos nas seções acima, reconhecendo que ainda há muito a se explorar nesses deslocamentos e nuances entre diferentes sentidos de cultura, religião e nação.

O feriado de Nossa Senhora Aparecida pode ser analisado como um caso em que a religião é também entendida como cultura, considerando que o catolicismo se construiu não só como parte da formação cultural do Brasil, mas principalmente como a própria totalidade da nação. É nesse sentido que a sua presença é tão naturalizada, a ponto de o que se entende por religião em nossa sociedade ser diretamente relacionado a ele, suas manifestações, sua estrutura e formas de presença pública.

O Dia da Consciência Negra, apesar de, em geral, não expor diretamente sua articulação com a dimensão religiosa, revela-nos um contexto em que a cultura engloba a religião, sendo esta última parte fundamental de uma tradição que precisa ser preservada e valorizada, e que também se associaria à composição da nação, recompondo-a a partir de outros termos. ${ }^{10}$

O Dia do Evangélico, por sua vez, indica uma situação em que a religião precisou se converter em cultura para ser reconhecida como parte da sociedade, ou como representante de uma crescente parcela da sociedade brasileira, embora sua orientação pareça estar mais voltada para o que pode vir a ser a nação no futuro. Avançando um pouco em relação à ideia de sua forma de atuação e presença como "cultura pública", sugiro que o cristianismo evangélico precisa se colocar como parte da cultura (mesmo que não acione a construção dessa cultura em termos históricos, ou "tradicionais") para que seja também incluído

10 Ver Giumbelli (2014b) para considerações em outro contexto de análise, que indicaria outra visão sobre a totalidade da nação. 
no que se considera como religião, garantindo assim outras possibilidades de atuação e participação em várias esferas da sociedade - ou várias partes -, o que nos leva a pensar que, talvez, não reivindique tanto sua parte no todo da cultura brasileira propriamente (não no presente, pelo menos). Entendo, porém, que essa lógica pode ser mais facilmente identificada em outros contextos (como a participação de evangélicos na política partidária, por exemplo), mas considero que o caso da data comemorativa faz igualmente parte desse processo. $\mathrm{E}$ com isso, pode-se propor que o evangélico se faz como cultura para ser feito também como religião, garantindo, por conseguinte, o lugar que a religião tem na ideia construída de cultura brasileira.

Outros elementos e deslocamentos são possíveis com a observação de distintos casos de análise, mas reforço como o exercício de reflexão em torno dessas três datas comemorativas vistas em conjunto nos ajudam a pensar alguns sentidos de religião e cultura e as diferentes posições que os grupos ocupam na constituição da nação.

\section{Referências}

ANDERSON, B. R. Comunidades imaginadas: reflexões sobre a origem e a difusão do nacionalismo. São Paulo: Companhia das Letras, 2008.

APÓS um ano de polêmica, 20 de novembro é sancionado como feriado em Porto Alegre. Sul21, 11 dez. 2015. Disponível em: <http://www.sul21.com.br/jornal/apos-um-ano-de-polemica-20-de-novembro-e-sancionado-como-feriado-em-porto-alegre/>. Acesso em: 14 dez. 2015.

BEAMAN, L. Battle over symbols: the "religion" of the minority versus the "culture" of the majority. Journal of Law and Religion, v. 28, n. 1, p. 67-104, 2012.

BOSISIO, I. A religião no calendário oficial: um mapeamento da legislação sobre feriados no Brasil. 2014. Dissertação (Mestrado em Antropologia Social)-Museu Nacional, Universidade Federal do Rio de Janeiro, Rio de Janeiro, 2014.

BRASIL. Lei $n^{\circ}$ 662, de 6 de abril de 1949. Declara Feriados Nacionais os Dias $1^{\circ}$ de Janeiro, $1^{\circ}$ de Maio, 7 de Setembro, 15 de Novembro e 25 de Dezembro. Rio de Janeiro, 1949. Disponível em: <http://www2.camara.gov.br/legin/fed/lei/1940-1949/lei-662-6-abril-1949-347136-normaatualizada-pl.pdf>. Acesso em: 3 abr. 2012. 
BRASIL. Lei $n^{0}$ 6.802, de 30 de junho de 1980. Declara Feriado Nacional o Dia 12 de Outubro, Consagrado a Nossa Senhora Aparecida, Padroeira do Brasil. Brasília, 1980. Disponível em: <http://www.planalto.gov.br/ccivil_03/leis/16802.htm>. Acesso em: 20 mar. 2012.

BRASIL. Lei $n^{\circ}$ 9.093, de 12 de setembro de 1995. Dispõe sobre feriados. Brasília, 1995. Disponível em: <http://www2.camara.leg.br/legin/fed/lei/1995/lei-9093-12-setembro-1995-348594-normaatualizada-pl.html>. Acesso em: 28 mar. 2012.

BRASIL. Lei $n^{\circ}$ 9.315, de 20 de novembro de 1996. Inscreve o nome de Zumbi dos Palmares no "Livro dos Heróis da Pátria". Brasília, 1996. Disponível em: <http://www2. camara.leg.br/legin/fed/lei/1996/lei-9315-20-novembro-1996-349074-publicacaooriginal-1-pl.html>. Acesso em: 24 jan. 2013.

BRASIL. Lei $n^{\circ} 10.639$, de 9 de janeiro de 2003. Altera a Lei $n^{\circ} 9.394$, de 20 de dezembro de 1996, que estabelece as diretrizes e bases da educação nacional, para incluir no currículo oficial da Rede de Ensino a obrigatoriedade da temática "História e Cultura Afro-Brasileira”, e dá outras providências. Brasília, 2003. Disponível em: <http:// www2.camara.leg.br/legin/fed/lei/2003/lei-10639-9-janeiro-2003-493157-publicacaooriginal-1-pl.html>. Acesso em: 24 jan. 2013.

BRASIL. Lei $n^{\circ} 12.328$, de 15 de setembro de 2010. Institui o Dia Nacional do Evangélico a ser comemorado no dia 30 de novembro de cada ano. Brasília, 2010. Disponível em: <http://www2.camara.leg.br/legin/fed/lei/2010/lei-12328-15-setembro-2010-608528-publicacaooriginal-129631-pl.html>. Acesso em: 1 ago. 2016.

BRASIL. Lei $n^{\circ} 12.519$, de 10 de novembro de 2011. Institui o Dia Nacional de Zumbi e da Consciência Negra. Brasília, 2011. Disponível em: <http://www2.camara. leg.br/legin/fed/lei/2011/lei-12519-10-novembro-2011-611762-publicacaooriginal-134215-pl.html>. Acesso em: 1 ago. 2016.

BRASIL. Constituição da República Federativa do Brasil de 1988. Texto consolidado até a Emenda Constitucional $n^{\circ}$ 70, de 29 de março de 2012. Brasília: Senado Federal, 2012.

BURITY, J. Cultura, identidade e inclusão social: o lugar da religião para seus atores e interlocutores. Debates do NER, Porto Alegre, v. 9, n. 14, p. 11-52, 2008.

CÂMARA de Porto Alegre aprova feriado da Consciência Negra no dia 20 de novembro. Sul21, 23 nov. 2015. Disponível em: <http://www.sul21.com.br/jornal/camara-de-porto-alegre-aprova-feriado-da-consciencia-negra-no-dia-20-de-novembro/>. Acesso em: 14 dez. 2015.

CARNEIRO DA CUNHA, M. "Cultura" e cultura: conhecimentos tradicionais e direitos intelectuais. In: CARNEIRO DA CUNHA, M. Cultura com aspas: e outros ensaios. São Paulo: Cosac Naify, 2009. p. 311-373. 
EAGLETON, T. Versões de cultura. In: EAGLETON, T. A ideia de cultura. São Paulo: Unesp, 2003. p. 9-50.

FERNANDES, R. C. Aparecida: nossa rainha, senhora e mãe, saravá!. In: SACHS, V. et al. Brasil e EUA: religião e identidade nacional. Rio de Janeiro: Graal, 1988. p. 85-111.

GIUMBELLI, E. O fim da religião: dilemas da liberdade religiosa no Brasil e na França. São Paulo: Attar, 2002.

GIUMBELLI, E. A presença do religioso no espaço público: modalidades no Brasil. Religião e Sociedade, Rio de Janeiro, v. 28, n. 2, p. 80-101, 2008.

GIUMBELLI, E. Cultura pública: evangélicos e sua presença na sociedade brasileira. In: GIUMBELLI, E. Símbolos religiosos em controvérsias. São Paulo: Terceiro Nome, 2014a. p. 189-207.

GIUMBELLI, E. Recomposing the Nation: conceptions and effects of heritage preservation in religious universes. Vibrant: Virtual Brazilian Anthropology, v. 11, n. 2, p. 442-469, 2014b.

HÄBERLE, P. Constituição e cultura: o direito ao feriado como elemento de identidade cultural do Estado constitucional. Rio de Janeiro: Lumen Juris, 2008.

LE GOFF, J. Calendário. In: ENCICLOPÉDIA EINAUDI: v. 1: memória-história. Lisboa: Imprensa Nacional: Casa da Moeda, 1984. p. 260-292.

MAFRA, C. A "arma da cultura" e os "universalismos parciais". Mana, Rio de Janeiro, v. 17, n. 3, p. 607-624, 2011.

MELO, I. Veto a feriado do Dia da Consciência Negra reabre debate na Capital. GaúchaZH, 8 jan. 2015. Disponível em: <https://gauchazh.clicrbs.com.br/porto-alegre/ noticia/2015/01/veto-a-feriado-do-dia-da-consciencia-negra-reabre-debate-na-capital-4677829.html>. Acesso em: 14 dez. 2015.

PAGNO, M. Feriado do Dia da Consciência Negra é aprovado, mas não será no dia 20. GaúchaZH, 16 nov. 2015. Disponível em: <https://gauchazh.clicrbs.com.br/porto-alegre/noticia/2015/11/feriado-do-dia-da-consciencia-negra-e-aprovado-mas-nao-sera-no-dia-20-cj5w516pwlbiexbj040m9utli.html>. Acesso em: 14 dez. 2015.

PORTO ALEGRE. Lei $n^{\circ} 11.971$, de 11 de dezembro de 2015. Altera a al. a do caput do art. $1^{\circ}$ da Lei $n^{\circ} 3.033$, de 30 de junho de 1967 - que fixa os feriados municipais -, e alterações posteriores, declarando feriado municipal o dia 20 de novembro, consagrado ao Dia da Consciência Negra e da Difusão da Religiosidade. Porto Alegre, 2015. Disponível em: <http://www2.portoalegre.rs.gov.br/netahtml/sirel/atos/Lei\%2011971>. Acesso em: 1 ago. 2016. 
RIO GRANDE DO SUL. Ministério Público do Estado do Rio Grande do Sul. Ação Direta de Inconstitucionalidade 606/2016, processo $n^{\circ}$ 70068409531. Disponível em: <https://www.mprs.mp.br/adins/custos-legis/2016/processos/606/>. Acesso em: 20 set. 2017.

SANCHIS, P. O repto pentecostal à "cultura católico-brasileira”. Revista de Antropologia, São Paulo, n. 37, p. 145-181, 1994.

STEIL, C. A. Catolicismo e cultura. In: VALLA, V. V. (Org.). Religião e cultura popular. Rio de Janeiro: DP\&A, 2001. p. 9-40.

WAGNER, R. A invenção da cultura. São Paulo: Cosac Naify, 2010.

WARNER, M. Publics and counterpublics. Public Culture, v. 14, n. 1, p. 49-90, 2002.

WILLIAMS, R. Cultura [culture]. In: WILLIAMS, R. Palavras-chaves: um vocabulário de cultura e sociedade. São Paulo: Boitempo, 2007. p. 117-124.

WILSON, E. "Culture" or "religion"? Understanding the popularity of the Passion. The Religion Factor, April 17, 2014. Disponível em: <http://religionfactor.net/2014/04/17/ culture-or-religion-understanding-the-popularity-of-the-passion/>. Acesso em: 2 ago. 2016.

WRIGHT, S. The politicization of “Culture”. Anthropology Today, v. 14, n. 1, p. 7-15, 1999.

Recebido: 30/09/2017 Aceito: 11/05/2018 | Received: 9/30/2017 Accepted:5/11/2018 